\section{Fluorescent Illumination with High Red-to-far-red Ratio Improves Resistance of Cucumber Seedlings to Powdery Mildew}

\author{
Toshio Shibuya ${ }^{1}$, Kaori Itagaki, Motoaki Tojo, Ryosuke Endo, and \\ Yoshiaki Kitaya \\ Graduate School of Life and Environmental Science, Osaka Prefecture \\ University, Gakuen-cho, Naka-ku, Sakai, Osaka 599-8531, Japan
}

Additional index words. artificial light, closed-type transplant production, Cucumis sativus, morphological characteristics, Sphaerotheca cucurbitae

\begin{abstract}
We investigated the effects of fluorescent illumination with a high red-to-far-red ratio (R:FR) on the resistance of cucumber (Cucumis sativus) seedlings to powdery mildew fungus (Sphaerotheca cucurbitae; PM). Seedlings were grown at a photosynthetic photon flux $(P P F)$ of $300 \mu \mathrm{mol} \cdot \mathrm{m}^{-2} \cdot \mathrm{s}^{-1}$ provided by fluorescent lamps with high $\mathrm{R}: \mathrm{FR}$ light $(\mathrm{R}: \mathrm{FR}=$ 7.0; $\left.F L_{H}\right)$ or low $R$ :FR light $\left(R: F R=1.1 ; F L_{L}\right)$ until cotyledons or the first foliage leaf were fully expanded. Spores of PM were then inoculated onto the leaves, and the seedlings were grown for 7 days (from cotyledon stage) or 9 days (from foliage-leaf stage) under $\mathrm{FL}_{\mathrm{H}}$. The number of $\mathrm{PM}$ colonies on $\mathrm{FL}_{\mathrm{H}}$ seedlings was $0.80 \times$ (cotyledons) and $0.62 \times$ (foliage leaves) the number on $\mathrm{FL}_{\mathrm{L}}$ seedlings. The reduction on the $\mathrm{FL}_{\mathrm{H}}$ seedlings was probably the result of changes in leaf morphological characteristics such as a thicker epidermal tissue as a result of the higher R:FR illumination. The number of PM colonies on cotyledons of the $\mathrm{FL}_{\mathrm{H}}$ seedlings was also smaller than that on seedlings grown under metal-halide lamps providing a spectrum similar to that of natural light $(R: F R=1.2)$.
\end{abstract}

Pest management after transplantation is essential in horticultural production, because early infections can spread throughout the crop. Therefore, in transplant production, the transplants are sprayed with pesticides before shipping.

Recently, closed-type transplant production systems (CTPS) that use artificial light have been developed as a way to produce highquality transplants regardless of the weather (Kozai, 2007; Kozai et al., 2006). The use of pesticides can be omitted, because the systems are closed to pathogens and their vectors. In addition, the growing of transplants in CTPS could further reduce the use of pesticides after transplantation through the improvement of plant resistance to pathogens by illumination with artificial light; plant resistance to diseases can be improved by illumination at particular wavelengths, notably ultraviolet (Brederode et al., 1991; Bridge and Klarman, 1973), violet (Wang et al., 2010), blue (Wang et al., 2010), or red (Islam et al., 2002; Khanam et al., 2005; Rahman et al., 2002; Schuerger and Brown, 1997; Wang et al., 2010).

Here, we focused on the R:FR of typical commercial fluorescent lamps commonly used in CTPS. Cucumber seedlings grown under fluorescent lamps with a high R:FR have thicker leaves and consequently higher photosynthetic ability (Shibuya et al., 2010a) and

Received for publication 14 Dec. 2010. Accepted for publication $18 \mathrm{Jan} .2011$.

${ }^{1}$ To whom reprint requests should be addressed; e-mail shibuya@envi.osakafu-u.ac.jp. lower attractiveness to sweetpotato whitefly (Shibuya et al., 2010b). The morphological and physiological changes are probably the result of responses that are the inverse of those typical of shade avoidance (Franklin, 2008; Smith and Whitelam, 1997). Typical commercial fluorescent lamps emit little FR irradiation and consequently have higher-than-natural R:FRs. Because morphological changes in leaves might affect plant resistance to pathogens (Szwacka et al., 2009), it might be possible to improve plant resistance by high R:FR illumination. To test this hypothesis, we investigated the effects of adaptation to illumination with high R:FR fluorescent light on the resistance of cucumber (Cucumis sativus) seedlings to PM (Sphaerotheca cucurbitae) in an inoculation test.

\section{Materials and Methods}

\section{Expt. 1}

Comparison of powdery mildew resistance of seedlings grown under high and low redto-far-red ratio fluorescent lamps. Cucumber 'Hokushin' seeds were sown in plastic pots (60 $\mathrm{mm}$ diameter, $55 \mathrm{~mm}$ height) containing vermiculite. The seedlings were grown in a growth chamber maintained at an air temperature of $28{ }^{\circ} \mathrm{C}$ and a relative humidity of $50 \%$ at a $P P F$ of $300 \mu \mathrm{mol} \cdot \mathrm{m}^{-2} \cdot \mathrm{s}^{-1}$ provided by fluorescent lamps with either high R:FR light (FPL55EX-N; Panasonic Corp., Kadoma, Japan; $F_{H}$ ) or low R:FR light (FL20S.FR.P Panasonic; $\mathrm{FL}_{\mathrm{L}}$ ). The ratio of red (600 to 700 $\mathrm{nm})$ to far-red (700 to $800 \mathrm{~nm}$ ) light of $\mathrm{FL}_{\mathrm{H}}$ was 7.0 and that of $\mathrm{FL}_{\mathrm{L}}$ was 1.1. The spectrum of $\mathrm{FL}_{\mathrm{H}}$ was similar to that of $\mathrm{FL}_{\mathrm{L}}$, except in FR (Fig. 1). The spectra were measured with a spectrometer (BLK-CXR-SR; StellarNet, Tampa, FL). To keep the $P P F$ at the leaf surfaces steady during the experiment, the distance between the light sources and the leaf surfaces was kept constant. The pots were placed in nutrient solution (A-type recipe of Otsuka House Solution; Otsuka Chemical Co. Ltd., Osaka, Japan) 5 to $10 \mathrm{~mm}$ deep. The composition of the solution in grams per $1000 \mathrm{~L}$ of tap water was total nitrogen, 260; phosphorus, 52; potassium, 336; calcium, 164; magnesium, 36; manganese, 1.2 ; boron, 0.5 ; iron, 2.7 ; copper, 0.03; zinc, 0.09; and molybdenum, 0.03. Electrical conductivity was $\approx 2.6 \mathrm{mS} \cdot \mathrm{cm}^{-1}$, and the $\mathrm{pH}$ was $\approx 6.5$ throughout the duration of the experiment.

We evaluated the resistance of cucumber seedlings to PM by compulsory inoculation testing at two growth stages: 10 seedlings were inoculated either when the cotyledons had fully expanded (cotyledon stage) or when the first foliage leaf had fully expanded (foliageleaf stage). The leaf areas in each treatment groups were effectively the same at inoculation. PM spore suspension was inoculated onto the adaxial surface from a hand sprayer. The suspension was prepared by scraping off the spores from PM-infected cucumber leaves in ion-exchanged water. We calculated the spore density on leaves from the spore density in the liquid (counted by eye under an optical microscope) and the volume of liquid per leaf area (evaluated by electric balance). The spore density was $4.2 \times 10^{4} \mathrm{~cm}^{-2}$ in the cotyledon stage and $3.0 \times 10^{4} \mathrm{~cm}^{-2}$ in the foliage-leaf stage. The inoculated seedlings were placed in a growth chamber (LPH-220SP; Nippon Medical \& Chemical Instruments Co. Ltd., Osaka,

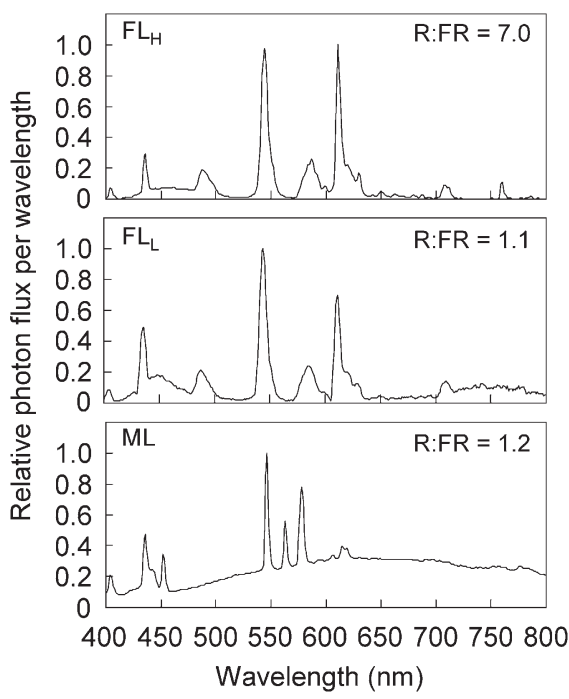

Fig. 1. Light spectra of lamps. $\mathrm{FL}_{\mathrm{H}}=$ fluorescent lamp with high red-to-far-red ratio (R:FR); $\mathrm{FL}_{\mathrm{L}}=$ fluorescent lamp with low R:FR; ML = metalhalide lamp that provides a spectrum similar to that of natural light. Relative photon fluxes per unit wavelength are expressed relative to the maximum. The R:FR was estimated by dividing the total photon flux from red light (600 to 700 $\mathrm{nm}$ ) by that from far-red light (700 to $800 \mathrm{~nm}$ ). 
Japan) maintained at an air temperature of 20 ${ }^{\circ} \mathrm{C}$, a relative humidity of $50 \%$, and a $P P F$ of $200 \mu \mathrm{mol} \cdot \mathrm{m}^{-2} \cdot \mathrm{s}^{-1}$ provided by fluorescent lamps (FL20SEX-N-HG; NEC Lighting Ltd., Tokyo, Japan) under a 12/12-h light/dark cycle. The spectrum of illumination from these lamps was the almost same as that of $\mathrm{FL}_{\mathrm{H}}$. We counted the PM colonies on the adaxial leaf surfaces by eye $7 \mathrm{~d}$ (cotyledon stage) and $9 \mathrm{~d}$ (foliage-leaf stage) after inoculation. Before inoculation, 10 (cotyledon stage) or eight (foliage-leaf stage) extra seedlings were taken for measurement of leaf dry mass and leaf area, from which the leaf mass per area (LMA) was calculated. The significance of differences between treatment means was determined by Student's $t$ test. Cross-sections of cotyledon in each treatment group were observed under a scanning electron microscope (SU-1510; Hitachi High-Technologies Corp., Tokyo, Japan). The experiments were conducted without replication.

\section{Expt. 2}

Comparison of powdery mildew resistance of seedlings grown under high red-to-farred ratio fluorescent lamps and metal-halide lamps. Cucumber seedlings were grown in growth chambers illuminated with $\mathrm{FL}_{\mathrm{H}}$ or metal-halide lamps (DR400/TL; Toshiba Lighting \& Technology Corp., Yokosuka, Japan; ML; R:FR $=1.2$ ) providing a spectrum similar to that of natural light (Fig. 1), and were then inoculated at the cotyledon stage. The density of inoculated spores on the leaf surface was $2.2 \times 10^{5} \mathrm{~cm}^{-2}$. We evaluated the resistance of seedlings to PM and calculated the LMA as in Expt. 1. The growing conditions (with the exception of the light source) and measuring methods were the same as in Expt. 1. The results could not be compared between experiments, because the density of spore inoculation per leaf area differed between the experiments.

\section{Results and Discussion}

The PM colonies were observed on the adaxial surface of leaves. The number of PM colonies on $\mathrm{FL}_{\mathrm{H}}$ seedlings was $0.80 \times$ (cotyledon) and $0.62 \times$ (foliage-leaf) that on $\mathrm{FL}_{\mathrm{L}}$ seedlings (Tables 1 and 2). This indicated that infection by PM was inhibited on leaves of cucumber seedlings raised under high R:FR fluorescent illumination. The LMA of $\mathrm{FL}_{\mathrm{H}}$ seedlings was $1.25 \times$ (cotyledon) and $1.20 \times$ (foliage-leaf) that of $\mathrm{FL}_{\mathrm{L}}$ seedlings (Tables 1 and 2). This difference indicated that leaves raised under high R:FR illumination were thicker than those raised under low R:FR illumination, as we previously found (Shibuya et al., 2010a, 2010b). The cotyledons of $\mathrm{FL}_{\mathrm{H}}$ seedlings were also thicker (Fig. 2) in the epidermal, palisade, and spongy tissues. These morphological differences between seedlings grown under a different light source might partly explain the slower development of PM colonies on $\mathrm{FL}_{\mathrm{H}}$ seedlings. The leaf morphological characteristics of cucumber (such as the ultrastructure of the cuticle and secondary walls) affect tolerance to pathogenic fungi (Szwacka et al., 2009). The cuticle structure

Table 1. Area and dry mass per leaf area (LMA) of cotyledons of cucumber seedlings grown under fluorescent lamps with high red-to-far-red $\left(\mathrm{R}: \mathrm{FR} ; \mathrm{FL}_{\mathrm{H}}\right)$ or with low R:FR $\left(\mathrm{FL}_{\mathrm{L}}\right)$ before inoculation and numbers of powdery mildew fungus (PM) colonies on the cotyledons $7 \mathrm{~d}$ after inoculation (Expt. 1).

\begin{tabular}{lccc}
\hline $\begin{array}{l}\text { Growing } \\
\text { condition }\end{array}$ & $\begin{array}{c}\text { Leaf area } \\
\left(\mathrm{cm}^{2} / \text { seedling }\right)\end{array}$ & $\begin{array}{c}\text { LMA } \\
\left(\mathrm{mg} \mathrm{DW} / \mathrm{cm}^{2}\right)\end{array}$ & $\begin{array}{c}\text { PM colonies per } \\
\text { seedling }\end{array}$ \\
\hline $\mathrm{FL}_{\mathrm{H}}$ & $19.5 \pm 0.5^{z}$ & $2.74 \pm 0.03$ & $68.7 \pm 4.5$ \\
$\mathrm{FL}_{\mathrm{L}}$ & $19.1 \pm 0.7$ & $2.20 \pm 0.04$ & $85.8 \pm 4.0$ \\
Significance $^{\mathrm{y}}$ & $\mathrm{NS}$ & $* *$ & $* *$ \\
\hline
\end{tabular}

${ }_{\mathrm{z}}$ Mean $\pm \operatorname{SE}(\mathrm{n}=10)$.

${ }_{\mathrm{NS}}^{\mathrm{y}}=$ non-significant $(P>0.05) ; * *$ significantly different between treatments at $P=0.01$ by $t$ test. $\mathrm{DW}=$ dry weight.

Table 2. Area and dry mass per leaf area (LMA) of first foliage leaf of cucumber seedlings grown under fluorescent lamps with high red-to-far-red $\left(\mathrm{R}: \mathrm{FR} ; \mathrm{FL}_{\mathrm{H}}\right)$ or with low R:FR $\left(\mathrm{FL}_{\mathrm{L}}\right)$ before inoculation and numbers of powdery mildew fungus (PM) colonies on the first foliage leaf $9 \mathrm{~d}$ after inoculation (Expt. 1).

\begin{tabular}{lccc}
\hline $\begin{array}{l}\text { Growing } \\
\text { condition }\end{array}$ & $\begin{array}{c}\text { Leaf area } \\
\left(\mathrm{cm}^{2} / \text { seedling }\right)\end{array}$ & $\begin{array}{c}\text { LMA } \\
\left(\mathrm{mg} \mathrm{DW} / \mathrm{cm}^{2}\right)\end{array}$ & $\begin{array}{c}\text { PM colonies per } \\
\text { seedling }\end{array}$ \\
\hline $\mathrm{FL}_{\mathrm{H}}$ & $37.8 \pm 2.3^{\mathrm{z}}$ & $1.93 \pm 0.04$ & $39.8 \pm 2.8$ \\
$\mathrm{FL}_{\mathrm{L}}$ & $35.0 \pm 2.2$ & $1.61 \pm 0.06$ & $64.1 \pm 5.1$ \\
Significance $^{\mathrm{y}}$ & $\mathrm{NS}$ & $* *$ & $*$ \\
\hline
\end{tabular}

${ }^{\mathrm{z}}$ Mean $\pm \mathrm{SE}\left(\mathrm{n}=8\right.$; PM colonies in $\left.\mathrm{FL}_{\mathrm{H}}, \mathrm{n}=10\right)$. Two $\mathrm{FL}_{\mathrm{L}}$ samples were removed because of leaf malformation of unknown cause.

${ }^{\mathrm{NS}}=$ non-significant $(P>0.05) ; *{ }^{*}{ }^{*}$ significantly different between treatments at $* P=0.05$ and $* * P=$ 0.01 by $t$ test.

$\mathrm{DW}=$ dry weight.
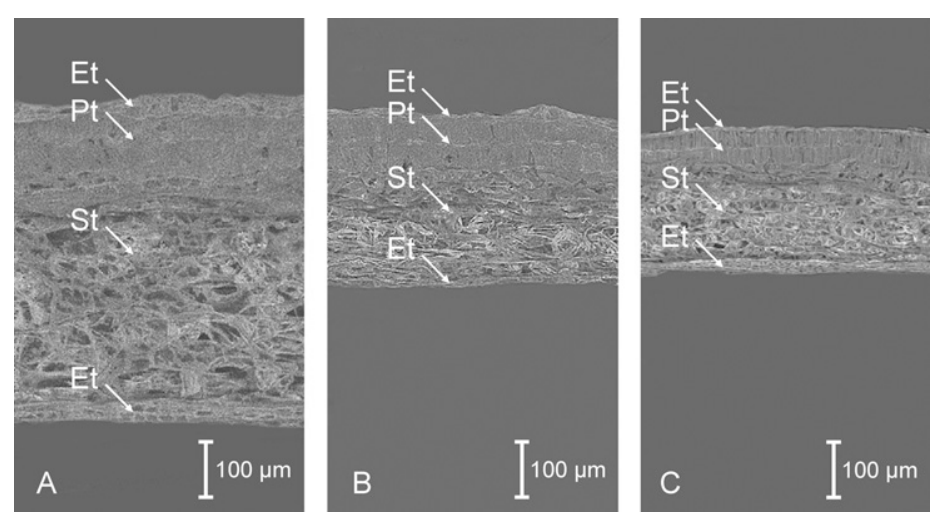

Fig. 2. Cross-sections of cotyledon of cucumber seedlings grown under (A) fluorescent lamps with high red-to-far-red ratio (R:FR) light $\left(\mathrm{FL}_{\mathrm{H}}\right)$, (B) fluorescent lamps with low R:FR light $\left(\mathrm{FL}_{\mathrm{L}}\right)$, or $(\mathbf{C})$ metalhalide lamps (ML) observed under a scanning electron microscope. $\mathrm{Et}=$ epidermal tissue; $\mathrm{Pt}=$ palisade tissue; $\mathrm{St}=$ spongy tissue. The images were retouched using a graphics editing program.

probably differed between the $\mathrm{FL}_{\mathrm{H}}$ and $\mathrm{FL}_{\mathrm{L}}$ seedlings in this experiment, because the morphological and physiological characteristics of $\mathrm{FL}_{\mathrm{H}}$ and $\mathrm{FL}_{\mathrm{L}}$ leaves were similar to those of sun leaves and shade leaves, respectively (Shibuya et al., 2010a, 2010b). The cuticle of sun leaves is thicker than that of shade leaves (Gratani et al., 2006).

The pest management technologies with providing specific wavelengths of light have been investigated for horticultural production in the greenhouse (Suthaparan et al., 2010a, 2010b). Red light could suppress sporulation of PM directly, and far-red light could stimulate conidial formation and negated the effect of red light; these direct effects indicate the presence and operation of photoreceptors (Suthaparan et al., 2010b). Our results indicate that the indirect effects of light quality on PM through the morphological changes of the host plant also should be taken into consideration for improving the pest management by controlling light quality. The light quality also could affect the plant's resistance through physiological defense mechanisms. Improved resistance of the plant to the pathogen under red light is correlated with plant antioxidant systems such as salicylic acid-mediated defense mechanisms (Khanam et al., 2005; Wang et al., 2010). Moreno et al. (2009) reported that phytochrome inactivation by FR caused a strong reduction of plant sensitivity to jasmonates, which are key regulators of plant immunity. Therefore, there is a great possibility that the development of $\mathrm{PM}$ colonies on $\mathrm{FL}_{\mathrm{H}}$ seedlings was inhibited not only thorough the morphological characteristics, but through the physiological defense mechanisms. To elucidate the mechanism of improved resistance under high R:FR illumination, we should closely examine the physiological responses in plant metabolism.

The differences in LMA, leaf structure, and number of $\mathrm{PM}$ colonies between $\mathrm{FL}_{\mathrm{H}}$ and ML were similar to those between $\mathrm{FL}_{\mathrm{H}}$ and 
Table 3. Area and dry mass per leaf area (LMA) of cotyledons of cucumber seedlings grown under fluorescent lamps with high red-to-far-red (R:FR; $\mathrm{FL}_{\mathrm{H}}$ ) or metal-halide lamps (ML) that provided a spectrum similar to that of natural light, before inoculation, and numbers of powdery mildew fungus (PM) colonies on the cotyledons $7 \mathrm{~d}$ after inoculation (Expt. 2).

\begin{tabular}{lccc}
\hline $\begin{array}{l}\text { Growing } \\
\text { condition }\end{array}$ & $\begin{array}{c}\text { Leaf area } \\
\left(\mathrm{cm}^{2} / \text { seedling }\right)\end{array}$ & $\begin{array}{c}\text { LMA } \\
\left(\mathrm{mg} \mathrm{DW} / \mathrm{cm}^{2}\right)\end{array}$ & $\begin{array}{c}\text { PM colonies per } \\
\text { seedling }\end{array}$ \\
\hline $\mathrm{FL}_{\mathrm{H}}$ & $16.0 \pm 0.4^{\mathrm{z}}$ & $3.51 \pm 0.07$ & $67.9 \pm 5.4$ \\
ML & $17.8 \pm 0.8$ & $3.21 \pm 0.07$ & $99.8 \pm 5.3$ \\
Significance $^{\mathrm{y}}$ & $\mathrm{NS}$ & $* *$ & $* *$ \\
\hline
\end{tabular}

${ }^{\mathrm{z}}$ Mean $\pm \mathrm{SE}(\mathrm{n}=10)$.

${ }^{\mathrm{y}} \mathrm{NS}=$ non-significant $(P>0.05) ;{ }^{*}$ significantly different between treatments at $P=0.01$ by $t$ test. $\mathrm{DW}=$ dry weight
$\mathrm{FL}_{\mathrm{L}}$ (Table 3; Fig. 2). This result indicated that cucumber seedlings adapted to $\mathrm{FL}_{\mathrm{H}}$ illumination had higher resistance to PM than seedlings adapted to metal-halide (ML) illumination and, because the spectrum of ML was similar to that of natural light, would also have higher resistance than seedlings adapted to natural light at the same $P P F$. This difference could occur in commercial transplant production using CTPS, because the daily PPF used in transplant production under artificial light can equal that of natural light (Kozai et al., 2006). The values of LMA were greater in Expt. 2 than in Expt. 1 (Tables 1 and 3), although the environmental conditions were almost the same for $\mathrm{FL}_{\mathrm{H}}$ seedlings in the two experiments. This difference was probably the result of differences in the timing of the experiment, although the true reasons are not clear. The absolute values obtained in each experiment could not be compared directly.

From these results, we concluded that the cucumber seedlings adapted to high R:FR of fluorescent illumination have higher resistance to PM. The changes in leaf morphological characteristics such as the thicker epidermal tissue may be one of the causes of this improvement. Growing transplants in CTPS by using $\mathrm{FL}_{\mathrm{H}}$ may reduce the use of pesticides not only during transplant production, but also after transplantation.
Moreno, J.E., Y. Tao, J. Chory, and C.L. Ballare. 2009. Ecological modulation of plant defense via phytochrome control of jasmonate sensitivity. Proc. Natl. Acad. Sci. USA 106:49354940.

Rahman, M.Z., Y. Honda, and S. Arase. 2002. Redlight-induced resistance in broad bean (Vicia faba L.) to leaf spot disease caused by Alternaria tenuissima. J. Phytopathol. 151:86-91.

Schuerger, A.C. and C.S. Brown. 1997. Spectral quality affects disease development of three pathogens on hydroponically grown plants. HortScience 32:96-100.

Shibuya, T., R. Endo, N. Hayashi, Y. Kitamura, and Y. Kitaya. 2010a. Potential photosynthetic advantages of cucumber (Cucumis sativus L.) seedlings grown under fluorescent lamps with high red:far-red light. HortScience 45:553-558.

Brederode, F.T., H.J.M. Linthorst, and J.F. Bol. 1991. Differential induction of acquired resistance and $P R$ gene expression in tobacco by virus infection, ethephon treatment, UV light and wounding. Plant Mol. Biol. 17:1117-1125.

Bridge, M.A. and W.L. Klarman. 1973. Soybean phytoalexin, hydroxyphaseollin, induced by ultraviolet irradiation. Phytopathology 63:606608.

Franklin, K.A. 2008. Shade avoidance. New Phytol. 179:930-944.

Gratani, L., F. Covone, and W. Larcher. 2006. Leaf plasticity in response to light of three evergreen species of the Mediterranean maquis. Trees (Berl.) 20:549-558.

Islam, S.Z., M. Babadoost, and Y. Honda. 2002. Effect of red light treatment of seedlings of pepper, pumpkin, and tomato on the occurrence of Phytophthora damping off. HortScience 37: 78-81.

Khanam, N.N., M. Ueno, J. Kihara, Y. Honda, and S. Arase. 2005. Suppression of red light-induced resistance in broad beans to Botrytis cinerea by salicylic acid. Physiol. Mol. Plant Pathol. 66:20-29.

Kozai, T. 2007. Propagation, grafting and transplant production in closed systems with artificial lighting for commercialization in Japan. Prop. Ornam. Plants 7:145-149.

Kozai, T., K. Ohyama, and C. Chun. 2006. Commercialized closed systems with artificial lighting for plant production. Acta Hort. 711: $61-70$.

Shibuya, T., J. Komuro, N. Hirai, Y. Sakamoto, R. Endo, and Y. Kitaya. 2010b. Preference of sweetpotato whitefly adults to cucumber seedlings grown under two different light sources. HortTechnology 20:873-876.

Smith, H. and G.C. Whitelam. 1997. The shade avoidance syndrome: Multiple responses mediated by multiple phytochromes. Plant Cell Environ. 20:840-844.

Suthaparan, A., A. Stensvand, D. Torre, M.L. Herrero, R.I. Pettersen, D.M. Gadoury, and H.R. Gislerød. 2010a. Continuous lighting reduces conidial production and germinability in the rose powdery mildew pathosystem. Plant Dis. 94:339 344.

Suthaparan, A., S. Torre, A. Stensvand, M.L. Herrero, R.I. Pettersen, D.M. Gadoury, and H.R. Gislerød. 2010b. Specific light-emitting diodes can suppress sporulation of Podosphaera pannosa on greenhouse roses. Plant Dis. 94: 1105-1110.

Szwacka, M., T. Tykarska, A. Wisniewska, M. Kuras, H. Bilski, and S. Malepszy. 2009. Leaf morphology and anatomy of transgenic cucumber lines tolerant to downy mildew. Biol. Plant. 53:697-701

Wang, H., J.Q. Yu, Y.P. Jiang, H.J. Yu, X.J. Xia, K. Shi, and Y.H. Zhou. 2010. Light quality affects incidence of powdery mildew, expression of defence-related genes and associated metabolism in cucumber plants. Eur. J. Plant Pathol. 127:125-135. 